Research paper

\title{
Hand hygiene compliance and behavioural determinants in a paediatric intensive care unit: An observational study
}

\author{
Aline S.C. Belela-Anacleto, RN, PhD \\ Denise M. Kusahara, RN, PhD * \\ Maria Angélica S. Peterlini, RN, PhD \\ Mavilde L.G. Pedreira, RN, PhD
}

Pediatric Nursing Department, Paulista Nursing School, Federal University of São Paulo, Napoleão de Barros Street, 754. Vila Clementino, São Paulo, 04024002, Office 113, Brazil

\section{A R T I C LE IN F O R M A T I O N}

\section{Article history:}

Received 14 December 2017

Received in revised form

19 February 2018

Accepted 20 February 2018

\section{Keywords:}

Behaviour

Guideline adherence

Hand hygiene

Paediatric intensive care units

\begin{abstract}
A B S T R A C T
Background: Hand hygiene is considered the single most effective means of reducing healthcareassociated infections, but improving and sustaining hand hygiene compliance remains a great challenge. Objectives: To compare hand hygiene compliance before and after interventions to promote adherence in a paediatric intensive care unit (PICU) and to identify predictors of intention to perform the behaviour "hand hygiene during patient care in the PICU".

Methods: A before and after study was conducted in three phases. Based on the World Health Organization guideline for hand hygiene compliance monitoring, 1261 hand hygiene opportunities were directly observed during routine patient care by two observers simultaneously, in a nine-bed PICU in Brazil, before and after infrastructure and educational interventions. To identify predictors of healthcare professionals' intention to perform the behaviour hand hygiene during patient care, a data collection instrument was designed based on the Theory of Planned Behaviour. Statistical analyses were undertaken using Chi-square test or the Fisher's exact test and regression analysis. A significance level of 5\% $(\mathrm{p}<0.05)$ was applied to all analyses.

Results: The hand hygiene compliance rate increased significantly from $27.3 \%$ in the "pre-intervention phase" to $33.1 \%$ in "phase 1 -post-intervention," to $37.0 \%$ in "phase 2 -post-intervention" ( $\mathrm{p}=.010)$. Perceived social pressure $(\mathrm{p}=.026)$ was a determinant factor of intention to perform the behaviour. Conclusions: Hand hygiene compliance raised significantly after infrastructure, educational, and performance feedback interventions. However, despite the significant effect of the implemented interventions, the overall hand hygiene compliance rate was low. Perceived social pressure characterised a determinant factor of intention to perform the behaviour "hand hygiene during patient care in the PICU", reinforcing the need for behaviour determinants analysis when designing promotional interventions.
\end{abstract}

๑ 2018 Australian College of Critical Care Nurses Ltd. Published by Elsevier Ltd. All rights reserved.

\section{Introduction}

Hand hygiene is the single most effective intervention to reduce healthcare-associated infections, a frequent adverse event in intensive care units (ICUs) and a major global challenge. ${ }^{1-3}$ Hand hygiene prevents endogenous and exogenous infections, cross-

\footnotetext{
* Corresponding author at: Napoleão de Barros Street, 754. Vila Clementino, São Paulo, CEP 04024-002, Brazil. Tel.: +55 1155764430.

E-mail addresses: aline.belela@unifesp.br (A.S.C. Belela-Anacleto), dkusahara@ unifesp.br (D.M. Kusahara), maria.angelica@unifesp.br (M.A.S. Peterlini), mpedreira@unifesp.br (M.L.G. Pedreira).
}

transmission of potential pathogens between patients, and environment contamination. ${ }^{4}$

Despite evidence on hand hygiene best practices, the adoption of the recommended practices in clinical settings is not consistently observed, and hand hygiene adherence among healthcare professionals is described as unacceptably low worldwide. $^{2-6}$ Improving and sustaining compliance remains a great challenge, and numerous studies describe a range of factors that influence hand hygiene behaviour, including professional role, clinical setting, cultural factors, and workload. ${ }^{7-10}$

Knowledge derived from the social sciences can provide support to the assessment of key determinants of hand hygiene behaviour 
among healthcare professionals. ${ }^{9}$ The use of multiple interventions has been recognised and recommended as an effective strategy for stimulating behavioural changes in multifaceted and complex environments. As part of the World Health Organization (WHO) Save Lives: Clean Your Hands initiative, the WHO Multimodal Hand Hygiene Improvement Strategy was developed. ${ }^{11}$ This is a conceptual framework with five key components: (i) system change; (ii) staff training; (iii) monitoring of hand hygiene indicators and performance feedback; (iv) reminders in the workplace; and (v) improvement of the institutional patient safety climate. ${ }^{1,11}$

The aims of this study were to compare hand hygiene compliance before and after interventions to promote adherence in a paediatric intensive care unit (PICU) in Brazil and to identify predictors of intention to perform the behaviour "hand hygiene during patient care in the PICU".

\section{Method}

A before and after study for hand hygiene compliance monitoring was conducted in a nine-bed PICU at a 700-bed tertiary care university hospital in São Paulo, Brazil. Approval from the institution's Research Ethics Committee and informed consent from healthcare workers were obtained.

The measures reported were the hand hygiene opportunities. A hand hygiene opportunity was defined as the moment during care activities that hand hygiene is necessary to interrupt germ transmission: before patient contact (indication 1), before clean/aseptic task (indication 2), after body fluid exposure risk (indication 3), after patient contact (indication 4), and after touching patient surroundings (indication 5). ${ }^{1,11,12}$

A sample of 378 hand hygiene opportunities per study moment, before and after two interventions periods (1134), was previously calculated for a statistical power of $80 \%$ with a confidence level of $95 \%$. At the end of the data collection, a total of 1261 hand hygiene opportunities were analysed. Hand hygiene compliance was calculated by the number of observed hand hygiene episodes per number of hand hygiene opportunities. ${ }^{11,12}$

Hand hygiene opportunities were observed by two trained nurses to conduct unobtrusive sessions, and PICU staff were aware of the monitoring. ${ }^{13}$ The observation sessions lasted 1 h. Observation and intervention phases are presented in Fig. 1.

To stimulate behavioural changes to hand hygiene improvement, a multimodal strategy based on WHO recommendations was implemented with five key components: (i) system change; (ii) staff training; (iii) monitoring of hand hygiene indicators and performance feedback; (iv) reminders in the workplace; and (v) improvement of the institutional patient safety climate.

Before the intervention, baseline data on hand hygiene compliance rates and infrastructure were collected in the 6 months preceding the intervention. An intervention was then implemented which consisted of system changes, staff training, and education. Conventional sinks were replaced by four large sinks with sensoractivated taps, wall-mounted soap and alcohol dispensers changed and repositioned at the point of care, alcohol containers with a pump were placed at the head and end of each bed, and individual portable dispensers of alcohol-based hand rub solution were distributed to healthcare professionals. During this period, hand hygiene knowledge was assessed before the first education session was carried out. Following the intervention period, observations were conducted.

A second intervention was then implemented which inducted administration of an instrument to identify predictors of intention to perform hand hygiene. A second education session was also held. The study aims were reinforced, and the results feedback is presented to PICU staff including medical and nursing leaders. At this time an institutional safety climate initiative and a mobilisation campaign entitled "Clean hands save lives. I do!" were launched as motivating factor. A pin with the campaign symbol was distributed to healthcare professionals. Posters were displayed showing hand hygiene indication concepts. Therefore, as suggest by WHO, we implemented training and education, observation, and feedback with reminders in the workplace.

Weekly performance feedback was provided to the PICU staff during the three observation phases with special emphasis on hand hygiene indications with lower adherence and on specific fault points identified by the observers. During the study, healthcare professionals interacted anonymously with the observers through a writing board available at the unit.

Pre-intervention: direct observation of $\mathrm{HH}$ compliance -410

$\mathrm{HHOs} /$ baseline assessment of $\mathrm{HH}$ practices and infrastructure/ performance feedback

\section{I}

Intervention 1: infrastructure and first educational session/ knowledge verification

I

Observation 1: direct observation of $\mathrm{HH}$ compliance -405 HHOs/ performance feedback

I

Intervention 2: second educational session/ verification of predictors of intention to perform $\mathrm{HH}$ behavior/ mobilisation

Observation 2: direct observation of HH compliance - 446

HHOs/ performance feedback

Fig. 1. Description of the study phases. $\mathrm{HH}$ - hand hygiene and $\mathrm{HHO}$ - hand hygiene opportunity. 


\section{دريافت فورى ـ ـ متن كامل مقاله}

\section{ISIArticles}

مرجع مقالات تخصصى ايران

ل امكان دانلود نسخه تمام متن مقالات انكليسى ل امكان دانلود نسخه ترجمه شده مقالات ل يذيرش سفارش ترجمه تخصصى $\checkmark$ ل امكان جستجو در آرشيو جامعى از صدها موضوع و هزاران مقاله ل امكان دانلود رايكان r صفحه اول هر مقاله

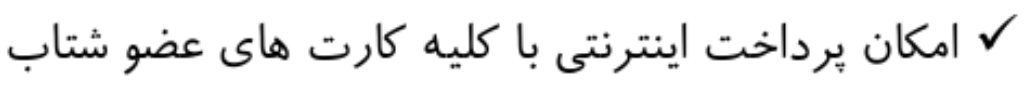
ل دانلود فورى مقاله پِ از برداخت آنلاين

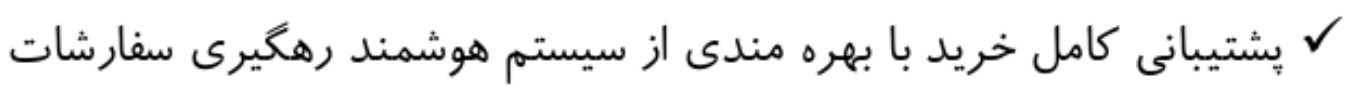

